AHP/ANP theory and its application in technological and economic development. The 90th anniversary of prof. Thomas I. Saaty

\title{
PAIRWISE COMPARISON MATRIX IN MULTIPLE CRITERIA DECISION MAKING
}

\author{
Gang KOU ${ }^{\mathrm{a}}$, Daji ERGU ${ }^{\mathrm{b}}$, Changsheng LIN ${ }^{\mathrm{c}}$, Yang CHEN ${ }^{\mathrm{a}}$ \\ ${ }^{a}$ School of Business Administration, Southwestern University of Finance and Economics, \\ Chengdu, China \\ ${ }^{b}$ Southwest University for Nationalities, Chengdu, China \\ ${ }^{c}$ Yangtze Normal University, Chongqing, China
}

Received 29 April 2016; accepted 02 July 2016

\begin{abstract}
The measurement scales, consistency index, inconsistency issues, missing judgment estimation and priority derivation methods have been extensively studied in the pairwise comparison matrix (PCM). Various approaches have been proposed to handle these problems, and made great contributions to the decision making. This paper reviews the literature of the main developments of the PCM. There are plenty of literature related to these issues, thus we mainly focus on the literature published in 37 peer reviewed international journals from 2010 to 2015 (searched via ISI Web of science). We attempt to analyze and classify these literatures so as to find the current hot research topics and research techniques in the PCM, and point out the future directions on the PCM. It is hoped that this paper will provide a comprehensive literature review on PCM, and act as informative summary of the main developments of the PCM for the researchers for their future research.
\end{abstract}

Keywords: Analytical Hierarchy Process (AHP), Analytical Network Process (ANP), consistency, pairwise comparison matrix (PCM), missing judgment estimation, priority derivation, multicriteria decision-making (MCDM).

JEL Classification: C44, D7, D81.

\section{Introduction}

The pairwise comparison technique has been widely used to tackle the subjective and objective judgments about qualitative and/or quantitative criteria in multi-criteria decision making (MCDM), especially in the Analytical Hierarchy Process (AHP) and Analytical Network Process (ANP), and usually denoted as pairwise comparison matrices (hereinafter, PCMs). The preference relations in the PCMs are filled in by the decision maker judgments, and presented using different measurement scales such as ratio scale (Saaty 1977), geometric 
scale (Lootsma 1989) and logarithmic scale (Ishizaka et al. 2010) etc. The judgments may be inconsistent and/or incomplete because of the limits of decision makers' expertise and capabilities or the complexity of the decision problems, and various approaches and models are proposed to handle these problems (Benítez et al. 2011; Ergu et al. 2011; Kou et al. 2014a). To evaluate the level of inconsistency in a PCM, different consistency indices have been proposed and compared (Brunelli et al. 2013a). The importance of criteria and the ranking of alternatives are often judged through the priority weights derived from a PCM, thus many prioritization approaches have been proposed to derive the priority weights from a PCM (Cavallo, D’Apuzzo 2011; Kou et al. 2014b).

There is an article reviewing the main developments in the AHP regarding the problem modelling, pairwise comparisons, judgment scales, derivation methods, consistency indices, incomplete matrix, synthesis of the weights, sensitivity analysis and group decisions from 1996 to 2010 (Ishizaka, Labib 2011). This paper extends some of the main developments through a literature review, and mainly focuses on the hot research topics in the PCM, including measurement scales, cardinal or ordinal inconsistency processing models, missing data estimation, consistency index and priority derivation methods. The reviewed literature were published in 37 peer reviewed international journals and searched via the ISI Web of science from 2010 to 2015. Based on the 93 journal articles collected, we attempt to analyze which topics on PCM were prevalently studied in recent years and which techniques were used to explore these issues, while which directions on the PCM remain to be studied in future. In addition, it is hoped that this paper will provide a comprehensive literature review on PCM, and act as informative summary of the main developments of the PCM for the researchers for their future researches.

The paper is organized as follows: Section 1 reviews the literature on the measurement scales, consistency indices, inconsistency processing models, missing judgments processing models and priority derivation methods in the multiplicative and additive PCM as well as interval PCM. The literature on Statistical (stochastic) approaches are reviewed in this section. Section 2 analyses the most prevalently research topics in the PCM, and some observations and discussions are presented in this section. The last Section concludes the paper.

\section{Review of the main research topics in the PCM}

When it comes to the pairwise comparison matrix (PCM), the existing researches usually focus on the measurement scales, consistency index, inconsistency issues and priority derivation methods either in multiplicative, additive or interval (fuzzy) PCM, therefore, the reviews of the main research topics in the PCM are grouped into two classes, i.e. multiplicative and additive PCM approach, interval PCM approach. Most of these researches were conducted based on optimization methods. Few of the articles focused on these issues from the statistical perspective, therefore, a review on the literature from the statistical perspective is presented separately in the following. 


\subsection{Multiplicative and additive PCM approaches}

\subsubsection{Measurement scales}

Five out of ninety-three articles (5.38\%) studied the measurement scales in the PCM.

Fülöp et al. (2010) focused on small scale construction for the PCM, and proposed to use the 3 -point scale ( 1 to 3 scale). They proved that the smaller scale has better mathematical foundations than larger ones. Kim et al. (2010) analyzed the consistency concept, and the 9-point scale was mapped to verbal scale. Based on the verbal scale, they proposed new criteria to solve the contradictory transitivity. The Monte-Carlo simulation based on bootstrap approach was conducted to derive the criteria. Choo, Wedley (2010) analyzed the issue of value changes between different unit measure when multiplying a ratio scale by a positive constant, and evaluated column averaging approaches for aggregating estimates with unknown units into overall values.

Dong et al. (2013) presented a novel framework for AHP users to generate numerical scales individually, which is based on the 2-tuple linguistic modeling of AHP scale problems.

Xia et al. (2015) presented the relative measure to calculate the relative values based on Abelian linearly ordered group (Alo-group).

\subsubsection{Consistency indices}

In a PCM, the relationship between judgments might be multiplicative, additive or fuzzy. For the different relationship, the consistency indices are different, and many consistency indices have been proposed to measure the consistency for a PCM. Among the reviewed 93 articles, 10 papers (10.75\%) focused on the inconsistency indices. Cavallo and D'Apuzzo (2010) presented an alo-group $\mathrm{G}=(\mathrm{G}, \odot, \leq)$ to unify the multiplicative, additive and fuzzy PCMs and a consistency index $I G(A)$ is developed to measure the consistency for the generated PCM.

Brunelli et al. (2013a) analyzed ten inconsistency indices of PCMs by numerical examples to investigate the degrees of their agreement. They are: $C I$, Index of determinants and $c 3$ $\left(C I^{*},-c_{3}\right)$, Squared differences index $(L S)$, the Geometric Consistency Index $(G C I)$, Harmonic Consistency Index $(H C I)$, Cavallo and D'Apuzzo $\left(I_{C D}\right)$, the relative error index $(R E)$, GoldenWang index $(G W)$, Koczkodaj index $(K)$, Ramík-Korviny index $\left(N I_{n}{ }^{\sigma}\right)$. Brunelli et al. (2013b) analyzed four consistency indices in the AHP in order to avoid redundancy in the selection of consistency preferences. The compared indices are: the Geometric Consistency Index (GCI), the index of Lamata and Peláez $\left(C I^{*}\right)$, the index $c_{3}$, the index $\rho$.

Ergu et al. (2014a) presented a maximum eigenvalue threshold as the consistency index for the ANP, and a block diagonal matrix was introduced to reduce the times of consistency test, then the inconsistent elements were identified and adjusted by an induced bias block diagonal comparison matrix.

Brunelli, Fedrizzi (2015a) analyzed the relationship between the consensus and preference aggregation of the PCM in group decisions. The following inconsistency indices, $C I, C I^{*}$, GCI, $I_{C D}$ and $K$, were analyzed and some properties of the inconsistency indices were defined. Brunelli, Fedrizzi (2015b) presented five axioms to characterize inconsistency indices, and some of the existing indices were tested by the proposed axioms. They found some of the 
inconsistency indices satisfy the proposed axioms while some are not. Meng, Chen (2015) proposed the multiplicative geometric consistent index (MGCI) to measure the consistency of multiplicative preference relations. Koczkodaj et al. (2016) presented an abelian linearly ordered group (alo-group) to analyze the iconsistency indicator map of PCM on a group, and proposed a new consistency index that called T-inconsistency indicator. Siraj et al. (2015) investigated various consistency measures by Monte-Carlo simulations, and proposed two measures (i.e. congruence and dissonance) for cardinal inconsistency and ordinal inconsistency. Xia, Chen (2015b) defined a consistency index $I_{\Omega}(A)$ for the PCM generated by Abelian linearly ordered group (alo-group), and consistency improving method has been proposed to deal with the inconsistency. Meanwhile, a consensus index $G I_{\Omega}(A)$ was defined to aggregate the individual PCMs. Grzybowski (2016) investigated the relationships among the values of the consistency indices, the "consistency" of the decision maker's judgments and prioritization results. The Monte Carlo simulations were conducted to analyze the performance of the most common inconsistency indices, and a new inconsistency index, called the average value of all "triad inconsistencies" (ATI) was proposed based on the KI index.

\subsubsection{Inconsistency processing models}

\subsubsection{Ordinal inconsistency}

The intransitivity or contradictory phenomenon between paired comparisons is regarded as ordinal inconsistency. four out of reviewed ninety-three papers (4.3\%) studied the ordinal inconsistency in a PCM.

Kéri (2010) employed the graph theoretic approach to deal with the intransitive and contradictory judgment matrices.

Siraj et al. (2012a) developed a heuristic algorithm to improve the ordinal consistency through identifying and eliminating the intransitive judgments in the PCMs. The near-optimal solution could be generated by the proposed model. In addition, Monte-Carlo simulation was conducted to collect the statistical evidence on the occurrence of three-way cycle in a PCM with acceptable consistency ratio.

Kou et al. (2014a) proposed a Hadamard product induced bias matrix (HPIBM) model to handle the cardinal and ordinal inconsistencies simultaneously. The proposed model is only based on the original matrix and is independent of the methods chosen to the prioritization methods.

Cavallo, D'Apuzzo (2015) analyzed the transitivity issue in the PCM over alo-group, and a tool was proposed to check the transitivity in the alo-group based PCM.

\subsubsection{Cardinal inconsistency}

Compared with the ordinal inconsistency, the cardinal inconsistency happened more often in the real world decision making, and much attention has been paid to this issue. Among the reviewed 93 papers, 17 papers $(18.28 \%)$ focused on the cardinal inconsistency issue, which are reviewed below.

Temesi (2010) discussed the relationship between the consistency of a PCM and the consistency of the decision maker. The error-free property is proposed to describe the latter consistency. 
Benítez et al. (2011) presented a linearization technique to handle the inconsistency issue in a PCM. Broadly speaking, the orthogonal projection is used to obtain the closest consistent matrix to an original inconsistent matrix, and the consistency has therefore been improved in a closed form. Ergu et al. (2011) proposed an induced bias matrix model to identify the most inconsistent elements in the PCM. The proposed model is capable of preserving most of the original information provided by the decision makers. To avoid the consistency issue and reduce the times of pairwise comparisons in a PCM, Hsu, Wang (2011) established a multi-criteria decision making with incomplete linguistic preference relations model (InLinPreRa) by using horizontal, vertical and oblique pairwise comparisons algorithm. In the proposed model, only $n-1$ pairwise comparisons need to be provided instead of $n(n-1) / 2$ times. Hou (2011) applied semirings algebra to discuss the properties of multiplicative reciprocal judgment matrices and additive reciprocal judgment matrices. In the proposed approach, optimization models were developed to find the nearest consistent judgment matrx.

Benítez et al. (2012) proposed an optimization method to improve the consistency of PCMs. The proposed model is based on the minimization of the distance between two matrices, and the number of decision variables is reduced to improve the computational efficiency.

Bozóki et al. (2013) conducted an empirical research on the empirical PCMs. The CR index proposed by Saaty and the CM proposed by Koczkodaj index were used to test the consistencies for the PCMs. They found that two factors impacted on the inconsistency, i.e. the type of the problem and the size of the matrix. In addition, They investigated the incomplete matrices so as to reveal the decision makers' behavior during the completing process.

For the dimensionality issue, Jalao et al. (2014a) proposed a PCM decomposition methodology to reduce the number of pairwise comparisons. The binary integer programming was used to decompose the PCM into smaller subsets, and the local priorities and the pivot element were obtained by minimizing the inner dependencies to estimate the global priorities. Ergu et al. (2014b) conducted simulation experiments for improving the consistency ratio of PCMs. The simulation was based on an induced bias matrix model. Zhang, H. et al. (2014) first defined the modified consistent PCM and an adjustable consistent PCM using the original inconsistent matrix, then developed an algorithm with segment tree to derive a consistent PCM with crisp or fuzzy elements. Based on three inconsistency indices (CR, CM and CI), Bozóki et al. (2014) employed a nonlinear mixed-integer optimization approach to find the minimal number of matrix elements in order to obtain appropriate modification and make the matrix acceptable. In addition, the proposed model can improve the consistency given the maximal number of modifiable matrix elements. Pereira, Costa (2014) presented a nonlinear programming model to improve the inconsistency by adjusting the original judgments in a minimum way. Girsang et al. (2014) proposed an ant algorithm based approach to find the minimal distance between the original PCM and the modified PCM in the AHP.

Kułakowski et al. (2015) proposed a concurrent inconsistency reduction algorithm to obtain a generalized PCM, aiming to deal with the large order of matrices in large decision 
support systems. Koczkodaj et al. (2015) conducted theoretical proof and empirical evidence of the reduction algorithm convergence for the distance-based inconsistency in the PCM. The Monte Carlo simulation was conducted to demonstrate the convergence speed of inconsistency reduction in pairwise comparisons. Xia, Chen (2015a) introduced the bilateral agreement to conduct group evaluation of alternatives, and employed the quasiarithmetic mean to ensure the consistency property of the PCMs in multi-criteria group decision making.

Zhang (2016) studied the properties of the consistency and consensus of multiplicative consistent reciprocal preference relations, and a consensus optimization model for group decision making was proposed to obtain consensus with the highest overall consensus level.

\subsubsection{Priority derivation methods}

How to derive the priority vectors from a PCM is one of the most important issues, and many prioritization methods have therefore been proposed. Ten out of reviewed ninetythree papers $(10.75 \%)$ studied the priority derivation methods.

Fedrizzi, Brunelli (2010) presented two straightforward methods for deriving the priority vector in the additively consistent PCM and multiplicatively consistent PCM respectively, and analyzed the relationships between the weight vectors and the reciprocal relations. Yuen (2010) proposed the analytic hierarchy prioritization process (AHPP) to provide the guidelines for selecting the most appropriate prioritization operator when the PCM is inconsistent. Nine prioritization operators and seven measurement criteria were used to validate the effectiveness of the proposed model.

Huo et al. (2011) developed a new parametric prioritization method (PPM) by three parameters to derive the priority vectors from a PCM and proved that a consistent complementary matrix can be transformed into a consistent reciprocal matrix, vice versa. Cavallo, D’Apuzzo (2011) applied the Abelian linearly ordered group (alo-group) to derive weights from a PCM. The proposed model satisfied the independence of scale-inversion condition. Dijkstra (2011) studied the properties of weight extraction methods for the PCMs by minimizing the suitable measures of inconsistency, "average error gravity", and recommended the geometric mean when considering the weight extraction.

Lin et al. (2013a) developed a logarithmic transformation based algorithm to obtain a nearer consistent matrix so as to derive the priority vector.

Kou, Lin (2014) proposed a cosine maximization method (CM) that is based on similarity measure to derive the priority vector for a PCM. The proposed model maximizes the sum of the cosine of the angle between the priority vector and each column vector of a PCM, and then reliable priority vector can be derived.

Tomashevskii (2015) analyzed the reliability of the eigenvector method (EM) based on "right-left asymmetry", "rank reversal" and reversal of "order of intensity of preference". This study shows that the numerical value of the errors completely relies on the inaccuracy of a measuring scale and inconsistent judgments. Jablonsky (2015) compared the three popular prioritization methods of PCM such as eigenvector method (EM), LLSM, LSM with other three goal programming methodologies, minimization of the sum of absolute and relative deviations (ASUM and RSUM) and minimization of the maximum deviation (absolute AMAX 
and relative RMAX). Kułakowski (2015a) analyzed the relationship between inconsistency of input and discrepancy of output, and two properties of the prioritization procedures were proposed based on the inconsistency and discrepancy indices.

\subsubsection{Missing judgments processing models}

In the decision making problem, incomplete judgments could occur because of various factors such as the incomplete information and limited expertise etc, thus the missing judgment estimation, the consistency issue of incomplete pairwise matrix have been paid more attention to in the PCM. Eight out of reviewed ninety-three papers (8.6\%) concentrated on the missing estimation issue.

Gomez-Ruiz et al. (2010) developed a model based on the Multi-Layer Perception (MLP) neural network to estimate the missing judgments in an incomplete PCM, and improve its consistency simultaneously.

Dopazo, Ruiz-Tagle (2011) defined a similarity function and a parametric compromise function to develop a logarithmic goal programming formulation computational method for incomplete PCMs in the group decision-making problem. Bozóki et al. (2011) extended the distance-based inconsistency indicator to the incomplete case in a PCM. They transformed the optimization problem into an equivalent linear programming problem so as to obtain an optimal solution.

Siraj et al. (2012b) proposed generation of all possible preferences from a set of PCMs. Based on a graph-theoretic approach, the pivotal combination concept was introduced to generate a forest with all spanning trees. In the proposed model, the following three factors such as the mean of all preferences, the variance, the enumerating all spanning trees (EAST) were used to deal with the final priority vector, the inconsistency measurement, the preferences estimation in an incomplete PCMs, respectively.

Fedrizzi, Giove (2013) proposed an optimal sequencing approach for incomplete PCMs in the case of large-dimensional problems. The fair involvement and the consistency of judgment were regarded as two criteria to define the choice rule and to obtain a rational questioning process.

Benítez et al. (2014) developed an approach to complete the incomplete judgments by minimizing the Frobenius norm based matrix distance.

Chen et al. (2015) proved that the connecting path method (CPM) can guarantee minimal geometric consistency index, and proposed a PCM based method to estimate the missing judgments whilst improve the consistency for an incomplete PCM. Ergu et al. (2016) proposed a revised geometric mean induced bias matrix to estimate the missing values for the incomplete decision matrix in the case of emergency management. The consistency ratio can be efficiently improved by the proposed model.

\subsection{Interval PCM approaches}

In addition to the multiplicative and additive judgment matrices, the interval judgment matrices are used to establish the decision maker's preference relations based on interval values. 


\subsubsection{Measurement scales}

There are only three papers (3.23\%) studied the measure scales. They are:

Dong et al. (2011) analyzed the individual numerical scale in the AHP, and a 2-tuple fuzzy linguistic model was proposed to evaluate the effect of the numerical scales.

Abdullah, Najib (2014) proposed a new preference scale by considering he membership function, the non-membership function and the degree of hesitation of interval-valued intuitionistic fuzzy numbers (IVIFN) simultaneously, and a modified interval-valued intuitionistic fuzzy weighted averaging was presented to define the weight entropy of the aggregated matrix of IVIFN.

Dong, Herrera-Viedma (2015) proposed a consistency-driven methodology to set the interval numerical scale without the need of the semantics used in interval type- 2 fuzzy sets.

\subsubsection{Consistency indices and Inconsistency processing models}

Seven papers $(7.53 \%)$ paid attention to the consistency indices and inconsistency issues in interval PCM.

Conde, de la Paz Rivera Pérez (2010) established an "interval judgment matrix" by determining a set of bounds on the preference ratios for the PCM, and a linear optimization problem was introduced to define a consistency index for the interval matrix, then the relative weights were derived by solving the linear optimization problem.

Pedrycz, Song (2011) applied the information granularity to investigate the consistency and the consensus of the individual PCMs in AHP based group decision making. The granular entries in the granular PCM was presented by intervals, and the inconsistency indices were minimized to increase the level of consensus within the group.

Dong et al. (2014) studied the consistency issues in interval PCMs, and a new consistency index of interval PCM was proposed based on logarithmic Manhattan distance, then linear programming models were presented to calculate the consistency indices for an interval PCM. A LP-based consistency improving model was also proposed for improving the consistency of interval PCMs.

Ramík (2015) employed the abelian linearly ordered group (alo-group) to handle the PCM with fuzzy entries, and two consistency indices were proposed to deal with the inconsistency of triangular fuzzy numbers (PCFN) matrices. Li et al. (2016) focused on the consistency ratio for interval multiplicative comparison matrices (IMCMs), and a geometric mean based index was proposed to test the indeterminacy ratio of an IMCM.

Wang (2015a) proposed a new triangular fuzzy arithmetic based transitivity equation to define consistent Triangular Fuzzy Preference Relation (TFPR), and an acceptable consistency was proposed for TFPRs. The normalized triangular fuzzy multiplicative weights were transformed into consistent TFPRs by geometric mean and uncertainty ration based transformation formulae. The weight vectors of TFPR were derived by a logarithmic least square model.

\subsubsection{Priority derivation methods}

There are 11 papers $(11.83 \%)$ studying the priority derivation methods. 
Torabi, Rafiei (2012) developed a single-decision-making optimization model along with two group-decision-making optimization model to derive the weights from fuzzy PCMs.

$\mathrm{Xu}$, Cai (2012) studied group decision making problems with interval multiplicative preference relations, and proposed two linear programming models to derive the weight from intervals multiplicative preference relations. Then, the continuous ordered weighted averaging operator or the continuous ordered weighted geometric operator was used to aggregate all the values in each weight interval.

Mirhedayatian et al. (2013) proposed a new approach for ranking the alternatives in fuzzy AHP by fuzzy data envelopment analysis. Lin, J. et al. (2013) proposed a new formula for ranking multiplicative interval weights in the AHP, and an approximation and adjustment (AAM) method was presented to obtain multiplicative triangular fuzzy weights. The geometric mean centroid of multiplicative triangular fuzzy weight was proposed to compare two multiplicative triangular fuzzy weights. Izadikhah (2013) employed the ranking function to transform the triangular fuzzy data into crisp one, then proposed the goal programming method to derive the fuzzy weights of criteria from fuzzy PCM.

Mohtashami (2014) proposed a Modified Fuzzy Logarithmic Least Square Model (MFLLSM) to derive the crisp priority vector from consistent and inconsistent fuzzy PCMs. The triangular shaped fuzzy number and trapezoidal shaped fuzzy numbers were used to present the fuzzy judgments for the first time. Zhang, F. et al. (2014) proposed an algorithm to derive the final priority interval weights for both consistent and inconsistent interval PCM.

Ramík (2015) studied the fuzzy PCM by Abelian linearly ordered group (Alo-group), and some concepts on the reciprocity and consistency as well as priority vector for fuzzy PCMs were generalized and analyzed. Chen, Xu (2015) presented a new fuzzy programming method (NFPM) to derive the priority vector from an interval PCM. Dutta, Guha (2015) proposed a novel approach to derive weights from the PCM with intuitionistic fuzzy numbers (IFNs), which generates crisp priority from PCM with IF. Meng et al. (2015) proposed two new methods to derive the interval priority vector from the interval preference relations based on the eigenvalue method and the row geometric mean method.

\subsubsection{Missing judgments processing models}

Five papers (5.38\%) proposed new approaches for estimating the missing judgments in the interval PCM.

Liu et al. (2012) proposed a goal programming model to complement the acceptable missing values in incomplete interval multiplicative preference relations (IMPR), which was based on the consistency property of IMPR, then a new algorithm was developed to obtain the priority vector from incomplete IMPR. Again, an interval weighted geometric averaging (IWGA) operator was proposed to aggregate the individual preference relations.

Wang, Chen (2014) focused on the consistency prioritization and completion of interval fuzzy preference relations, then a geometric mean based uncertainty ratio, a logarithmic least squares based method and a logarithm least squares completion approach were proposed to deal with the uncertainty, interval weights, inconsistency modification and missing values estimation for interval fuzzy preference relation (IFPR) respectively. Ramík (2014) studied the relations between transitivity and consistency of fuzzy PCMs and mul- 
tiplicative preferences PCMs. A new approach was proposed to estimate the missing values in the fuzzy PCMs. Xu et al. (2014) focused on the incomplete interval fuzzy preference relation, and a new approach was proposed to handle the AHP for group decision making with incomplete IFPR.

Zhang et al. (2015) defined the concept of additive consistent hesitant fuzzy preference relations, and the following three concepts were introduced, i.e., incomplete hesitant fuzzy preference relation, acceptable incomplete hesitant fuzzy preference relation, and additive consistent incomplete hesitant fuzzy preference relation, then two estimation procedures were proposed to estimate the missing values in the incomplete hesitant fuzzy preference relation.

\subsection{Statistical (stochastic) approaches}

In recent years, some statistical or stochastic approaches were developed to measure the consistency level of the PCM and derive the priority weights from the PCM. However, only thirteen papers $(13.98 \%)$ out of the ninety-three reviewed papers investigated the consistency indices, inconsistency issues and priority derivation methods from the statistical analysis perspective, very few articles have addressed the missing judgment estimation from the statistical analysis perspective.

\subsubsection{Consistency indices and Inconsistency processing models}

Five papers (5.38\%) focused on the consistency indices and inconsistency processing models. Tsyganok (2010) analyzed the effectiveness of some methods of expert estimate aggregation in the PCM based on the simulation of possible expert errors. The genetic algorithm was suggested to search the maximum possible deviation in the PCM.

Liu et al. (2011) proposed a method for solving the stochastic multiple criteria decision making (SMCDM) problem. The dominance degree matrix was constructed by comparisons of probability distributions, and PROMETHEE II was used to built an overall dominance degree matrix as so to obtain the final ranking order of alternatives.

Entani, Sugihara (2012) defined the uncertainty indices for intervals from the perspectives of entropy in probability, sum or maximum of widths, or ignorance, then obtained the intervals of attributes by minimizing the uncertainty indices.

Lin et al. (2013b) developed an improved statistical approach for consistency test of the PCM by combining the test hypotheses and maximum likelihood estimation. Based on the significance level.

Lin et al. (2014) proposed a new statistical approach to deal with consistency issue in a PCM based on the hypothesis test and the random consistency index. The proposed approach is not only capable of identifying the deviation of consistency index (CI), but also reflecting the significance level of testing the consistency.

\subsubsection{Priority derivation methods}

There are eight papers (8.6\%) using statistical analysis approaches for deriving the weights from the PCM. 
Bernasconi et al. (2010) transformed a rigorous statistical analysis equation about the ratio scale of the PCM in AHP into a regression model, and then a method of the statistical analysis was conducted to estimate the priority weights in the AHP that takes into account the distortions caused by the subjective weighting function. Zhang et al. (2010) proposed a novel method based on the stochastic dominance degree (SDD) to solve a discrete stochastic multiple criteria decision-making (MCDM) problem, and an approach based on PROMETHEE-II was proposed to derive the priority weights for ranking alternatives.

Jalao et al. (2014b) used the method-of-moments methodology to fit the varying stochastic preferences of the DM into beta stochastic pairwise comparisons. Zhu and $\mathrm{Xu}$ (2014) proposed numerical preference relations (NPRs) to be the general form of the four existing preferences relations, i.e. multiplicative preference relations (MPRs), fuzzy preference relations (FPRs), interval MPRs (IV-MPRs) and interval FPRs (IV-FPRs). Then a stochastic preference analysis (SPA) method was developed to aid the decision makers (DMs) in decision making.

Lin, Kou (2015) proposed a Bayesian revision method for improving the individual PCMs by making full use of the prior distribution for parameters and sample information. Wang (2015b) defined a geometric mean based uncertainty index to measure the uncertainty level of the established interval matrix. In addition, a parameterization approximate relation was presented to show the relation between the normalized interval probabilities and the established interval matrix. Then a two-stage procedure was proposed to obtain the interval probabilities from A multiplicative reciprocal comparison matrix. Kułakowski (2015b) presented a new iterative heuristic rating estimation algorithm that tries to deal with the situation when exact estimations for some concepts (stimulus) CK are a priori known and fixed. Yaraghi et al. (2015) used a simulation approach to compare the results of AHP with Monte Carlo analytic hierarchy process (MCAHP) under different levels of uncertainty. The results showed that the performance of AHP is not statistically different from the performance of MCAHP if the variation in different PCM is lower than 0.24 , otherwise the MCAHP provides more precise rankings.

\section{Observations and discussion}

In the previous reviews, 93 journal articles published in 37 peer reviewed international journals from 2010 to 2015, were collected through ISI web of science. These articles mainly focused on the main developments in the PCM, including the measurement scales, consistency indices, inconsistency processing models, priority derivation methods, missing judgments processing models. Table 1 shows the distribution of the reviewed articles by journals. Obviously, the journal European Journal of Operational Research contains the most relevant articles, comprising 15 out of the 93 articles reviewed (16.13\%), followed by Information Sciences (9.68\%) and Annals of Operations Research (6.45\%), while 21 journals contains only 1 related literature respectively.

Some observations based on the reviews are made and discussed in the following.

As classified in the previous sections, the pairwise comparison matrices can be generally grouped into three types: multiplicative, additive and interval (fuzzy) PCM. 
Table 1. Distribution of the selected articles by journals

\begin{tabular}{|c|c|c|c|}
\hline & Name of the journal & $\begin{array}{c}\text { Amount } \\
(\%)\end{array}$ & Percentage \\
\hline 1 & European Journal of Operational Research & 15 & 16.13 \\
\hline 2 & Information Sciences & 9 & 9.68 \\
\hline 3 & Annals of Operations Research & 6 & 6.45 \\
\hline 4 & Applied Soft Computing & 5 & 5.38 \\
\hline 5 & Expert Systems with Applications & 5 & 5.38 \\
\hline 6 & Central European Journal of Operations Research & 4 & 4.3 \\
\hline 7 & Applied Mathematics and Computation & 4 & 4.3 \\
\hline 8 & Computers \& Industrial Engineering & 4 & 4.3 \\
\hline 9 & Soft Computing & 3 & 3.23 \\
\hline 10 & Applied Mathematical Modelling & 3 & 3.23 \\
\hline 11 & Fuzzy Sets and Systems & 3 & 3.23 \\
\hline 12 & Mathematical and Computer Modelling & 3 & 3.23 \\
\hline 13 & Computers \& Operations Research & 2 & 2.15 \\
\hline 14 & Fundamenta Informaticae & 2 & 2.15 \\
\hline 15 & IEEE Transactions On Fuzzy Systems & 2 & 2.15 \\
\hline 16 & International Journal of Intelligent Systems & 2 & 2.15 \\
\hline 17 & Artificial Intelligence and Soft Computing & 1 & 1.08 \\
\hline 18 & Abstract and Applied Analysis & 1 & 1.08 \\
\hline 19 & Group Decision and Negotiation & 1 & 1.08 \\
\hline 20 & International Journal of General Systems & 1 & 1.08 \\
\hline 21 & International Journal of Computers Communications \& Cont & 1 & 1.08 \\
\hline 22 & IEEE Transactions on Cybernetics & 1 & 1.08 \\
\hline 23 & IEEE Transactions on Engineering Management & 1 & 1.08 \\
\hline 24 & Information Fusion & 1 & 1.08 \\
\hline 25 & International Journal of Approximate Reasoning & 1 & 1.08 \\
\hline 26 & International Journal of Computational Intelligence Systems & 1 & 1.08 \\
\hline 27 & Journal of Intelligent \& Fuzzy Systems & 1 & 1.08 \\
\hline 28 & Journal of Physics: Conference Series & 1 & 1.08 \\
\hline 29 & Journal of the Operational Research & 1 & 1.08 \\
\hline 30 & Journal of the Korean Institute of Industrial Engineers & 1 & 1.08 \\
\hline 31 & Journal of the Operational Research Society & 1 & 1.08 \\
\hline 32 & Mathematical Problems in Engineering & 1 & 1.08 \\
\hline 33 & Management Science & 1 & 1.08 \\
\hline 34 & Neural Computing and Applications & 1 & 1.08 \\
\hline 35 & Technological and Economic Development of Economy & 1 & 1.08 \\
\hline 36 & The International Journal of Advanced Manufacturing Technology & 1 & 1.08 \\
\hline \multirow[t]{2}{*}{37} & Transactions on Computational Collective Intelligence & 1 & 1.08 \\
\hline & Total & 93 & \\
\hline
\end{tabular}


It can be seen from Figure 1 that the researches on the first two types of PCM (54 papers, 58\%) were more popular than the interval (fuzzy) PCM (26 papers, 27.96\%). Moreover, 13 papers utilized the statistical analysis methods to study the above issues, accounting for $13.54 \%$ of the reviewed 93 papers.

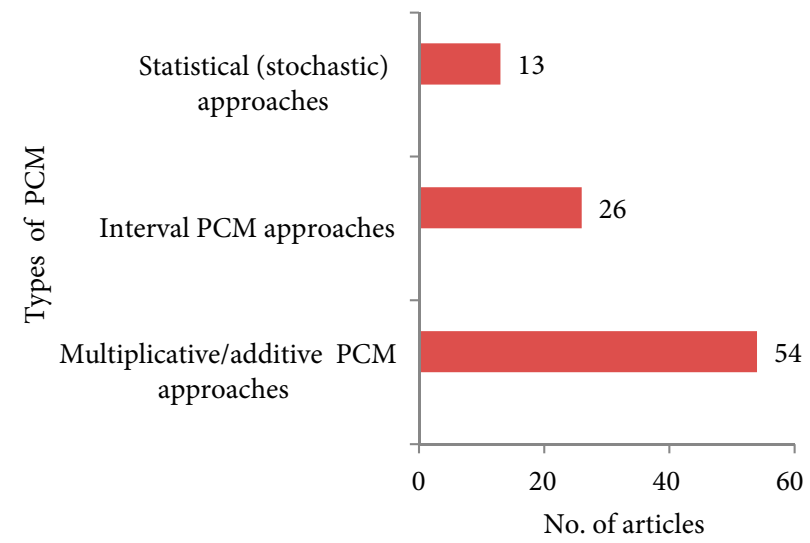

Fig. 1. The distribution of researches on three classes of PCMs

In the multiplicative and additive PCMs, Figure 2 shows that the most prevalent research topics is cardinal inconsistency issue, and fewer researches focused on the ordinal inconsistency and measure scales. For the measure scales in the multiplicative and additive PCMs, Table 2 (see Appendices) shows that the attention has been paid to the size of scale, the verbal scale, numerical scale and relative measure scale. In the studies on consistency indices, some researchers focus on the comparison among the existing consistency indices in order to provide a guideline for selecting appropriate consistency index, some concentrate on the analysis of the properties of the inconsistency indices so as to propose axioms to characterize inconsistency indices, while much attention has been paid to developing new consistency indices for improving the test efficiency, as shown in Table 3 (see Appendices).

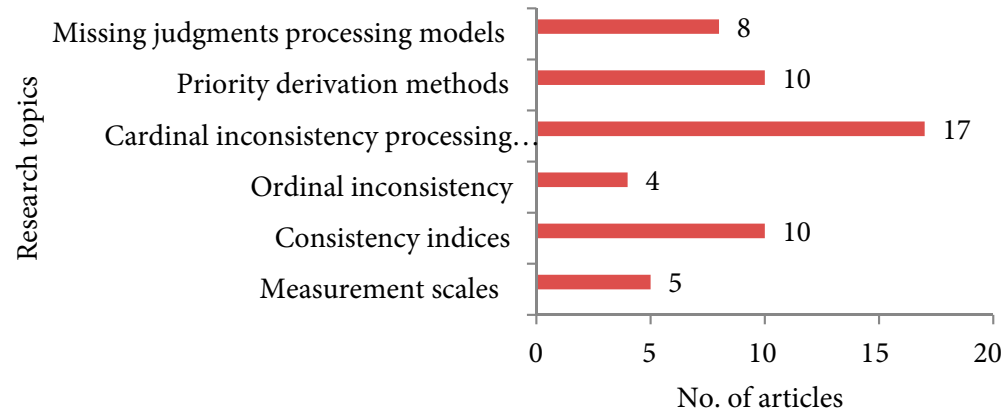

Fig. 2. The distribution of researches on the main developments of multiplicative and additive PCMs 
On the inconsistency processing models, the inconsistency issue in a PCM can be grouped into two classes: ordinal inconsistency (intransitivity) and cardinal inconsistency, in which the latter is more popular than the former, as shown in Table 4 (see Appendices). In addition, the graph theoretic approach is usually used to study the ordinal inconsistency. There are various approaches for cardinal inconsistency, including linearization technique and nonlinear optimization approach. Specifically, the consistency ratio can be improved by identifying and modifying the most inconsistent elements, minimizing the distance between the inconsistent PCM and constructed near-consistent PCM, reducing the number of pairwise comparisons and so on.

For the priority derivation methods, Table 5 (see Appendices) shows that some researchers focus on the analysis and comparison among the existing prioritization approaches and provide guidelines for selecting the appropriate derivation method, while others concentrate on developing new derivation methods such as the parametric method, logarithmic transformation based algorithm and cosine maximization method.

The approaches on missing judgments processing models include Multi-Layer Perception (MLP) neural network, a logarithmic goal programming formulation method, linear programming method, graph-theoretic approach, optimal sequencing approach, Frobenius norm based matrix distance minimization approach, connecting path method (CPM) based method and geometric mean induced bias matrix approach, as shown in Table 6 (see Appendices).

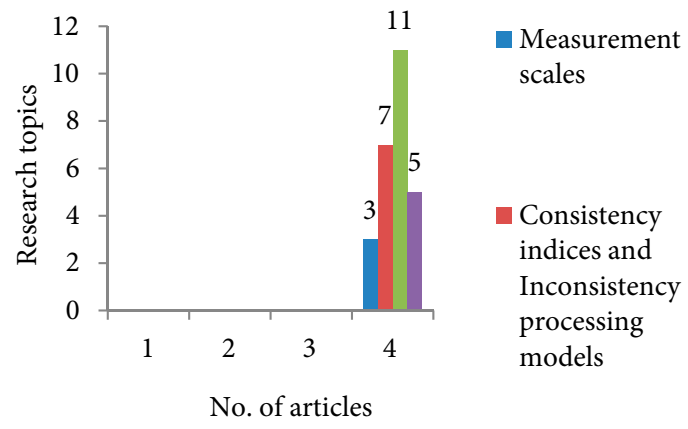

Fig. 3. The distribution of researches on the main developments of interval (fuzzy) PCMs

In the studies on interval (fuzzy) PCM, Figure 3 shows that only three papers focused on measure scales. Much attention still has been paid to the consistency indices, inconsistency processing models, priority derivation methods and missing judgments processing models, in which the most frequently studied topic is the priority derivation methods (11 papers out of 93 papers, $11.83 \%$ ), followed by consistency indices and inconsistency processing models (7 papers, $7.53 \%$ ), missing judgments processing models (5 papers, $5.38 \%$ ) and measure scales (3 papers, 3.23\%). It can be seen from Table 7 (see Appendices) that fuzzy techniques were used in the measure scales. Different from the multiplicative and additive PCM, there are more integrated approaches in the interval PCM. For instance, Table 8 (see Appendices) indicates that researchers first proposed a new consistency index, then developed related models to improve the consistency or derive the weights for interval 
PCM. The employed approaches contain linear programming model, information granularity, logarithmic Manhattan distance, geometric mean, abelian linearly ordered group (alo-group) and logarithmic least square model etc.

To derive the priority weights for an interval PCM, various techniques have been employed in the reviewed articles, including linear or nonlinear progamming methods, fuzzy data envelopment analysis, approximation and adjustment (AAM) method, Fuzzy Logarithmic Least Square Model, Abelian linearly ordered group (Alo-group) and fuzzy programming method (FPM) etc, as shown in Table 9 (see Appendices).

For the missing judgments estimation problem in interval PCM, we found that two paper focused on consistency, weight prioritization and missing judgments estimation concurrently, and the other three papers paid attention to both consistency and missing judgments estimation procedures. Table 10 also presents that the used techniques include goal programming model, logarithm least squares optimization and mathematical optimization etc.

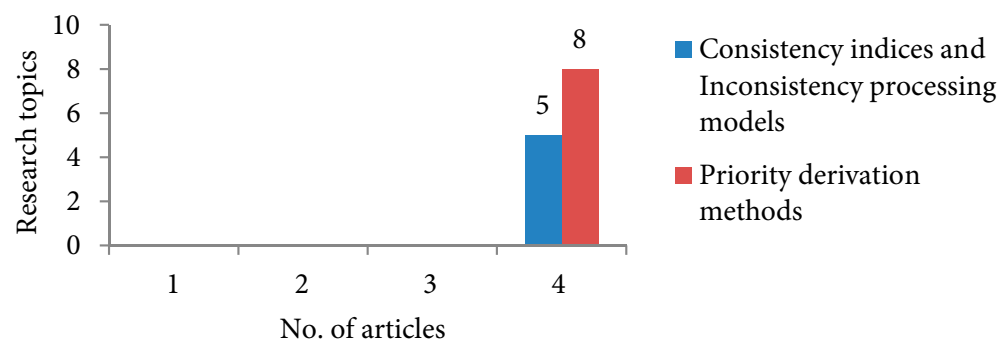

Fig. 4. The distribution of researches on the main developments of statistical approaches

Compared with the previous approaches in multiplicative, additive PCMs and interval PCM, Figure 4 shows that few articles involved in the above mentioned research issues using statistical approach, in which 5 out of ninety-three articles concentrated on the consistency indices and inconsistency processing models using statistical approach such as probability distribution, test hypotheses and maximum likelihood estimation etc (see Appendices, Table 11), while 8 papers focused on the priority derivations. The employed techniques include regression model, statistical analysis, stochastic dominance degree (SDD), PROMETHEE-II, method-of-moments methodology, beta stochastic distribution, non-linear programming mode, stochastic preference analysis (SPA) method, ayesian method, geometric mean, parameterization approximate relation, iterative heuristic rating estimation algorithm and Monte Carlo analytic hierarchy process (MCAHP) etc, as shown in Table 12.

\section{Conclusions}

This paper is based on a literature review on the main research topics in the pairwise comparison matrix (PCM) from year 2000 to 2015. First, it was found that various approaches were proposed to deal with the measurement scales, consistency index, inconsistency issues and priority derivation methods either in multiplicative, additive or interval (fuzzy) PCM. The most popular research topic is the inconsistency issue, the employed techniques mainly 
include linearization technique and nonlinear optimization approach. Second, it was noticed that the priority derivation approaches were paid more attention when the statistical analysis methods are employed. In addition, integrated approaches become popular than single method.

In the era of big data, all the approaches proposed for the above issues in the PCM will face big challenges, especially with the increase of dimension of matrix size, the existing approaches and algorithms for consistency test, inconsistent element identification and modification priority derivation methods are not capable of dealing with these issues for the PCM with large dimensions. The missing judgments in the PCM with large size will be another big challenge in the big data environment. Therefore, new approaches remain to be studied under the big data environment in future.

\section{Acknowledgements}

This research has been partially supported by grants from the National Natural Science Foundation of China (\#71373216, \#71471149 and \#71222108), grants from Academic Degree Programs Construction at Southwest University for Nationalities (\#2016XWDS1601, B0304) and Major project of the National Social Science Foundation of China (\# 15ZDB153).

\section{References}

Abdullah, L.; Najib, L. 2014. A new preference scale mcdm method based on interval-valued intuitionistic fuzzy sets and the analytic hierarchy process, Soft Computing 20(2): 511-523. http://dx.doi.org/10.1007/s00500-014-1519-y

Benítez, J.; Carrión, L.; Izquierdo, J.; Pérez-García, R. 2014. Characterization of consistent completion of reciprocal comparison matrices, Abstract and Applied Analysis 2014: 1-12. http://dx.doi.org/10.1155/2014/349729

Benítez, J.; Delgado-Galván, X.; Izquierdo, J.; Pérez-García, R. 2011. Achieving matrix consistency in AHP through linearization, Applied Mathematical Modelling 35(9): 4449-4457. http://dx.doi.org/10.1016/j.apm.2011.03.013

Benítez, J.; Delgado-Galván, X.; Izquierdo, J.; Pérez-García, R. 2012. Improving consistency in AHP decision-making processes, Applied Mathematics and Computation 219(5): 2432-2441. http://dx.doi.org/10.1016/j.amc.2012.08.079

Bernasconi, M.; Choirat, C.; Seri, R. 2010. The analytic hierarchy process and the theory of measurement, Management Science 56(4): 699-711. http://dx.doi.org/10.1287/mnsc.1090.1123

Bozóki, S.; Dezső, L.; Poesz, A.; Temesi, J. 2013. Analysis of pairwise comparison matrices: an empirical research, Annals of Operations Research 211(1): 511-528. http://dx.doi.org/10.1007/s10479-013-1328-1

Bozóki, S.; Fülöp, J.; Koczkodaj, W. W. 2011. An LP-based inconsistency monitoring of pairwise comparison matrices, Mathematical and Computer Modelling 54(1-2): 789-793. http://dx.doi.org/10.1016/j.mcm.2011.03.026

Bozóki, S.; Fülöp, J.; Poesz, A. 2014. On reducing inconsistency of pairwise comparison matrices below an acceptance threshold, Central European Journal of Operations Research 23(4): 849-866. http://dx.doi.org/10.1007/s10100-014-0346-7 
Brunelli, M.; Canal, L.; Fedrizzi, M. 2013a. Inconsistency indices for pairwise comparison matrices: a numerical study, Annals of Operations Research 211(1): 493-509.

http://dx.doi.org/10.1007/s10479-013-1329-0

Brunelli, M., Critch, A.; Fedrizzi, M. 2013b. A note on the proportionality between some consistency indices in the AHP, Applied Mathematics and Computation 219(14): 7901-7906. http://dx.doi.org/10.1016/j.amc.2013.01.036

Brunelli, M.; Fedrizzi, M. 2015a. Axiomatic properties of inconsistency indices for pairwise comparisons, Journal of the Operational Research 66(1): 15. http://dx.doi.org/10.1057/jors.2013.135

Brunelli, M.; Fedrizzi, M. 2015b. Boundary properties of the inconsistency of pairwise comparisons in group decisions, European Journal of Operational Research 240(3): 765-773. http://dx.doi.org/10.1016/j.ejor.2014.07.045

Cavallo, B.; D’Apuzzo, L. 2010. Characterizations of consistent pairwise comparison matrices over abelian linearly ordered groups, International Journal of Intelligent Systems 25(10): 1035-1059. http://dx.doi.org/10.1002/int.20438

Cavallo, B.; D’Apuzzo, L. 2011. Deriving weights from a pairwise comparison matrix over an alo-group, Soft Computing 16(2): 353-366. http://dx.doi.org/10.1007/s00500-011-0746-8

Cavallo, B.; D’Apuzzo, L. 2015. Reciprocal transitive matrices over abelian linearly ordered groups: Characterizations and application to multi-criteria decision problems, Fuzzy Sets and Systems 266: 33-46. http://dx.doi.org/10.1016/j.fss.2014.07.005

Chen, K.; Kou, G.; Michael Tarn, J. ; Song, Y. 2015. Bridging the gap between missing and inconsistent values in eliciting preference from pairwise comparison matrices, Annals of Operations Research 235(1): 155-175. http://dx.doi.org/10.1007/s10479-015-1997-z

Chen, L.; Xu, Z. 2015. A new fuzzy programming method to derive the priority vector from an interval reciprocal comparison matrix, Information Sciences 316: 148-162. http://dx.doi.org/10.1016/j.ins.2015.04.015

Choo, E. U.; Wedley, W. C. 2010. Estimating ratio scale values when units are unspecified, Computers \& Industrial Engineering 59(2): 200-208. http://dx.doi.org/10.1016/j.cie.2010.04.001

Conde, E.; de la Paz Rivera Pérez, M. 2010. A linear optimization problem to derive relative weights using an interval judgement matrix, European Journal of Operational Research 201(2): 537-544. http://dx.doi.org/10.1016/j.ejor.2009.03.029

Dijkstra, T. K. 2011. On the extraction of weights from pairwise comparison matrices, Central European Journal of Operations Research 21(1): 103-123. http://dx.doi.org/10.1007/s10100-011-0212-9

Dong, Y.; Chen, X.; Li, C.; Hong, W.; Xu, Y. 2014. Consistency issues of interval pairwise comparison matrices, Soft Computing 19(8): 2321-2335. http://dx.doi.org/10.1007/s00500-014-1426-2

Dong, Y. C.; Herrera-Viedma, E. 2015. Consistency-driven automatic methodology to set interval numerical scales of 2-tuple linguistic term sets and its use in the linguistic GDM with preference relation, IEEE Transactions on Cybernetics 45(4): 780-792.

http://dx.doi.org/10.1109/TCYB.2014.2336808

Dong, Y.; Hong, W.-C.; Xu, Y.; Yu, Sh. 2011. Selecting the individual numerical scale and prioritization method in the analytic hierarchy process: a 2-tuple fuzzy linguistic approach, IEEE Transactions On Fuzzy Systems 19(1): 12. http://dx.doi.org/10.1109/TFUZZ.2010.2073713

Dong, Y.; Hong, W.-C.; Xu, Y.; Yu, S. 2013. Numerical scales generated individually for analytic hierarchy process, European Journal of Operational Research 229(3): 654-662. http://dx.doi.org/10.1016/j.ejor.2013.03.019

Dopazo, E.; Ruiz-Tagle, M. 2011. A parametric GP model dealing with incomplete information for group decision-making, Applied Mathematics and Computation 218(2): 514-519. http://dx.doi.org/10.1016/j.amc.2011.05.094 
Dutta, B.; Guha, D. 2015. Preference programming approach for solving intuitionistic fuzzy AHP, International Journal of Computational Intelligence Systems 8(5): 977-991.

http://dx.doi.org/10.1080/18756891.2015.1099904

Ergu, D.; Kou, G.; Peng, Y.; Shi, Y. 2011. A simple method to improve the consistency ratio of the pair-wise comparison matrix in ANP, European Journal of Operational Research 213(1): 246-259. http://dx.doi.org/10.1016/j.ejor.2011.03.014

Ergu, D.; Kou, G.; Peng, Y.; Yang, X. 2014b. Simulation experiments for improving the consistency ratio of reciprocal matrices, International Journal Of Computers Communications \& Control 9(4): 11. http://dx.doi.org/10.15837/ijccc.2014.4.1165

Ergu, D.; Kou, G.; Peng, Y.; Zhang, M. 2016. Estimating the missing values for the incomplete decision matrix and consistency optimization in emergency management, Applied Mathematical Modelling 40(1): 254-267. http://dx.doi.org/10.1016/j.apm.2015.04.047

Ergu, D.; Kou, G.; Shi, Y.; Shi, Y. 2014a. Analytic network process in risk assessment and decision analysis, Computers \& Operations Research 42: 58-74. http://dx.doi.org/10.1016/j.cor.2011.03.005

Entani, T.; Sugihara, K. 2012. Uncertainty index based interval assignment by Interval AHP, European Journal of Operational Research 219(2): 379-385. http://dx.doi.org/10.1016/j.ejor.2012.01.010

Fedrizzi, M.; Brunelli, M. 2010. On the priority vector associated with a reciprocal relation and a pairwise comparison matrix, Soft Computing 14(6): 639-645.

http://dx.doi.org/10.1007/s00500-009-0432-2

Fedrizzi, M.; Giove, S. 2013. Optimal sequencing in incomplete pairwise comparisons for large-dimensional problems, International Journal of General Systems 42(4): 366-375.

http://dx.doi.org/10.1080/03081079.2012.755523

Fülöp, J.; Koczkodaj, W. W.; Szarek, S. J. 2010. A different perspective on a scale for pairwise comparisons, in I. N. T. Nguyen, R. Kowalczyk. Transactions on computational collective intelligence. Berlin, Heidelberg: Springer Berlin Heidelberg, 71-84. http://dx.doi.org/10.1007/978-3-642-15034-0_5

Girsang, A. S.; Tsai, C.-W.; Yang, C.-S. 2014. Ant algorithm for modifying an inconsistent pairwise weighting matrix in an analytic hierarchy process, Neural Computing and Applications 26(2): 313327. http://dx.doi.org/10.1007/s00521-014-1630-0

Gomez-Ruiz, J. A.; Karanik, M.; Peláez, J. I. 2010. Estimation of missing judgments in AHP pairwise matrices using a neural network-based model, Applied Mathematics and Computation 216(10): 2959-2975. http://dx.doi.org/10.1016/j.amc.2010.04.009

Grzybowski, A. Z. 2016. New results on inconsistency indices and their relationship with the quality of priority vector estimation, Expert Systems with Applications 43: 197-212. http://dx.doi.org/10.1016/j.eswa.2015.08.049

Hou, F. 2011. A Semiring-based study of judgment matrices: properties and models, Information Sciences 181(11): 2166-2176. http://dx.doi.org/10.1016/j.ins.2011.01.020

Hsu, S.-C.; Wang, T.-C. 2011. Solving multi-criteria decision making with incomplete linguistic preference relations, Expert Systems with Applications 38(9): 10882-10888. http://dx.doi.org/10.1016/j.eswa.2011.02.123

Huo, L.-A.; Lan, J.; Wang, Z. 2011. New parametric prioritization methods for an analytical hierarchy process based on a pairwise comparison matrix, Mathematical and Computer Modelling 54(11-12): 2736-2749. http://dx.doi.org/10.1016/j.mcm.2011.06.062

Izadikhah, M. 2013. Deriving fuzzy weights of criteria from inconsistent fuzzy comparison matrices by using goal programming method, Journal of Intelligent \& Fuzzy Systems 25(1): 69-80.

Ishizaka, A.; Balkenborg, D.; Kaplan, T. 2010. Influence of aggregation and measurement scale on ranking a compromise alternative in AHP, Journal of the Operational Research Society 62: 700-710. http://dx.doi.org/10.1057/jors.2010.23 
Ishizaka, A.; Labib, A. 2011. Review of the main developments in the analytic hierarchy process, Expert Systems with Applications 38(11): 14336-14345. http://dx.doi.org/10.1016/j.eswa.2011.04.143

Jablonsky, J. 2015. Analysis of selected prioritization methods in the analytic hierarchy process, Journal of Physics: Conference Series 622: 012033. http://dx.doi.org/10.1088/1742-6596/622/1/012033

Jalao, E. R.; Wu, T.; Shunk, D. 2014a. An intelligent decomposition of pairwise comparison matrices for large-scale decisions, European Journal of Operational Research 238(1): 270-280. http://dx.doi.org/10.1016/j.ejor.2014.03.032

Jalao, E. R.; Wu, T.; Shunk, D. 2014b. A stochastic AHP decision making methodology for imprecise preferences, Information Sciences 270: 192-203. http://dx.doi.org/10.1016/j.ins.2014.02.077

Kéri, G. 2010. On qualitatively consistent, transitive and contradictory judgment matrices emerging from multiattribute decision procedures, Central European Journal of Operations Research 19(2): 215-224. http://dx.doi.org/10.1007/s10100-010-0138-7

Kim, J.-B.; Cho, Y.-G.; Yong-Gon, C.; Yun-Bae, K.; Keun-Tae, C. 2010. New criteria for the consistency in reasonable pairwise comparison matrices, Journal of the Korean Institute of Industrial Engineers 36(1): 6.

Koczkodaj, W. W.; Kosiek, M.; Szybowski, J.; Xu, D. 2015. Fast convergence of distance-based inconsistency in pairwise comparisons, Fundamenta Informaticae 137(3): 12.

Koczkodaj, W. W.; Szybowski, J.; Wajch, E. 2016. Inconsistency indicator maps on groups for pairwise comparisons, International Journal of Approximate Reasoning 69: 81-90. http://dx.doi.org/10.1016/j.ijar.2015.11.007

Kou, G.; Ergu, D.; Shang, J. 2014a. Enhancing data consistency in decision matrix: adapting Hadamard model to mitigate judgment contradiction, European Journal of Operational Research 236(1): 261271. http://dx.doi.org/10.1016/j.ejor.2013.11.035

Kou, G.; Lin, C. 2014. A cosine maximization method for the priority vector derivation in AHP, European Journal of Operational Research 235(1): 225-232. http://dx.doi.org/10.1016/j.ejor.2013.10.019

Kou, G.; Peng, Y.; Wang, G. 2014b. Evaluation of clustering algorithms for financial risk analysis using MCDM methods, Information Science 275: 1012. http://dx.doi.org/10.1016/j.ins.2014.02.137

Kułakowski, K. 2015a. A heuristic rating estimation algorithm for the pairwise comparisons method, Central European Journal of Operations Research 23(1): 187-203. http://dx.doi.org/10.1007/s10100-013-0311-x

Kułakowski, K. 2015b. On the properties of the priority deriving procedure in the pairwise comparisons method, Fundamenta Informaticae 139(4): 7. http://dx.doi.org/10.3233/FI-2015-1240

Kułakowski, K.; Juszczyk, R.; Ernst, S. 2015. A concurrent inconsistency reduction algorithm for the pairwise comparisons method, Artificial Intelligence and Soft Computing 9120: 214-222. http://dx.doi.org/10.1007/978-3-319-19369-4_20

Lootsma, F. 1989. Conflict resolution via pairwise comparison of concessions, European Journal of Operational Research 40: 109-116. http://dx.doi.org/10.1016/0377-2217(89)90278-6

Li, K. W.; Wang, Z.-J.; Tong, X. 2016. Acceptability analysis and priority weight elicitation for interval multiplicative comparison matrices, European Journal of Operational Research 250(2): 628-638. http://dx.doi.org/10.1016/j.ejor.2015.09.010

Lin, C.; Kou, G. 2015. Bayesian revision of the individual pair-wise comparison matrices under consensus in AHP-GDM, Applied Soft Computing 35: 802-811. http://dx.doi.org/10.1016/j.asoc.2015.02.041

Lin, C.; Kou, G.; Ergu, D. 2013a. A heuristic approach for deriving the priority vector in AHP, Applied Mathematical Modelling 37(8): 5828-5836. http://dx.doi.org/10.1016/j.apm.2012.11.023

Lin, C.; Kou, G.; Ergu, D. 2013b. An improved statistical approach for consistency test in AHP, Annals of Operations Research 211(1): 289-299. http://dx.doi.org/10.1007/s10479-013-1413-5 
Lin, C.; Kou, G.; Ergu, D. 2014. A statistical approach to measure the consistency level of the pairwise comparison matrix, Journal of the Operational Research Society 65(9): 1380-1386. http://dx.doi.org/10.1057/jors.2013.92

Lin, J.; Lan, J.; Jiang, Y. 2013. Some models for generating and ranking multiplicative weights, Computers \& Industrial Engineering 65(4): 586-593. http://dx.doi.org/10.1016/j.cie.2013.05.006

Liu, Y.; Fan, Z.-P.; Zhang, Y. 2011. A method for stochastic multiple criteria decision making based on dominance degrees, Information Sciences 181(19): 4139-4153. http://dx.doi.org/10.1016/j.ins.2011.05.013

Liu, F.; Zhang, W.-G.; Wang, Z.-X. 2012. A goal programming model for incomplete interval multiplicative preference relations and its application in group decision-making, European Journal of Operational Research 218(3): 747-754. http://dx.doi.org/10.1016/j.ejor.2011.11.042

Meng, F.; Chen, X. 2015. An approach to incomplete multiplicative preference relations and its application in group decision making, Information Sciences 309: 119-137.

http://dx.doi.org/10.1016/j.ins.2015.03.020

Meng, F.; Chen, X.; Zhu, M.; Lin, J. 2015. Two new methods for deriving the priority vector from interval multiplicative preference relations, Information Fusion 26: 122-135. http://dx.doi.org/10.1016/j.inffus.2014.12.002

Mirhedayatian, M.; Jelodar, M. J. ; Adnani, S.; Akbarnejad, M.; Saen, R. F. 2013. A new approach for prioritization in fuzzy AHP with an application for selecting the best tunnel ventilation system, The International Journal of Advanced Manufacturing Technology 68(9-12): 2589-2599. http://dx.doi.org/10.1007/s00170-013-4856-6

Mohtashami, A. 2014. A novel meta-heuristic based method for deriving priorities from fuzzy pairwise comparison judgments, Applied Soft Computing 23: 530-545. http://dx.doi.org/10.1016/j.asoc.2014.05.030

Pedrycz, W.; Song, M. 2011. Analytic Hierarchy Process (AHP) in group decision making and its optimization with an allocation of information granularity, IEEE Transactions on Fuzzy Systems 19(3): 12. http://dx.doi.org/10.1109/TFUZZ.2011.2116029

Pereira, V.; Costa, H. G. 2014. Nonlinear programming applied to the reduction of inconsistency in the AHP method, Annals of Operations Research 229(1): 635-655. http://dx.doi.org/10.1007/s10479-014-1750-z

Ramík, J. 2014. Incomplete fuzzy preference matrix and its application to ranking of alternatives, International Journal of Intelligent Systems 29(8): 787-806. http://dx.doi.org/10.1002/int.21663

Ramík, J. 2015. Pairwise comparison matrix with fuzzy elements on alo-group, Information Sciences 297: 236-253. http://dx.doi.org/10.1016/j.ins.2014.11.010

Saaty, T. 1977. A scaling method for priorities in hierarchical structures, Journal of Mathematical Psychology 15: 234-281. http://dx.doi.org/10.1016/0022-2496(77)90033-5

Siraj, S.; Mikhailov, L.; Keane, J. 2012a. A heuristic method to rectify intransitive judgments in pairwise comparison matrices, European Journal of Operational Research 216(2): 420-428. http://dx.doi.org/10.1016/j.ejor.2011.07.034

Siraj, S.; Mikhailov, L.; Keane, J. A. 2012b. Enumerating all spanning trees for pairwise comparisons, Computers \& Operations Research 39(2): 191-199. http://dx.doi.org/10.1016/j.cor.2011.03.010

Siraj, S.; Mikhailov, L.; Keane, J. A. 2015. Contribution of individual judgments toward inconsistency in pairwise comparisons, European Journal of Operational Research 242(2): 557-567. http://dx.doi.org/10.1016/j.ejor.2014.10.024

Temesi, J. 2010. Pairwise comparison matrices and the error-free property of the decision maker, Central European Journal of Operations Research 19(2): 239-249.

http://dx.doi.org/10.1007/s10100-010-0145-8 
Tomashevskii, I. L. 2015. Eigenvector ranking method as a measuring tool: formulas for errors, European Journal of Operational Research 240(3): 774-780. http://dx.doi.org/10.1016/j.ejor.2014.07.050

Torabi, S. A.; Rafiei, H. 2012. An optimization framework towards prioritization in fuzzy comparison matrices, Expert Systems with Applications 39(1): 638-646. http://dx.doi.org/10.1016/j.eswa.2011.07.055

Tsyganok, V. 2010. Investigation of the aggregation effectiveness of expert estimates obtained by the pairwise comparison method, Mathematical and Computer Modelling 52(3-4): 538-544. http://dx.doi.org/10.1016/j.mcm.2010.03.052

Wang, Z.-J. 2015a. Consistency analysis and priority derivation of triangular fuzzy preference relations based on modal value and geometric mean, Information Sciences 314: 169-183. http://dx.doi.org/10.1016/j.ins.2015.03.074

Wang, Z.-J. 2015b. Uncertainty index based consistency measurement and priority generation with interval probabilities in the analytic hierarchy process, Computers \& Industrial Engineering 83: 252-260. http://dx.doi.org/10.1016/j.cie.2015.02.013

Wang, Z.-J.; Chen, Y.-G. 2014. Logarithmic least squares prioritization and completion methods for interval fuzzy preference relations based on geometric transitivity, Information Sciences 289: 59-75. http://dx.doi.org/10.1016/j.ins.2014.08.009

Xia, M.; Chen, J. 2015a. Multi-criteria group decision making based on bilateral agreements, European Journal of Operational Research 240(3): 756-764. http://dx.doi.org/10.1016/j.ejor.2014.07.035

Xia, M.; Chen, J. 2015b. Consistency and consensus improving methods for pairwise comparison matrices based on Abelian linearly ordered group, Fuzzy Sets and Systems 266: 1-32. http://dx.doi.org/10.1016/j.fss.2014.07.019

Xia, M.; Chen, J.; Zhang, J.2015. Multi-criteria decision making based on relative measures, Annals of Operations Research 229(1): 791-811. http://dx.doi.org/10.1007/s10479-015-1847-z

Xu, Z.; Cai, X. 2012. Deriving weights from interval multiplicative preference relations in group decision making, Group Decision and Negotiation 23(4): 695-713. http://dx.doi.org/10.1007/s10726-012-9315-5

Xu, Y.; Patnayakuni, R.; Tao, F.; Wang, H. 2014. Incomplete interval fuzzy preference relations for supplier selection in supply chain management, Technological and Economic Development of Economy 21(3): 379-404. http://dx.doi.org/10.3846/20294913.2013.876688

Yaraghi, N.; Tabesh, P.; Guan, P.; Zhuang, J. 2015. Comparison of AHP and Monte Carlo AHP under different levels of uncertainty, IEEE Transactions on Engineering Management 62(1): 10. http://dx.doi.org/10.1109/TEM.2014.2360082

Yuen, K. K. F. 2010. Analytic hierarchy prioritization process in the AHP application development: a prioritization operator selection approach, Applied Soft Computing 10(4): 975-989. http://dx.doi.org/10.1016/j.asoc.2009.08.041

Zhang, H. 2016. Group decision making based on multiplicative consistent reciprocal preference relations, Fuzzy Sets and Systems 282: 31-46. http://dx.doi.org/10.1016/j.fss.2015.04.009

Zhang, Y.; Fan, Z.-P.; Liu, Y. 2010. A method based on stochastic dominance degrees for stochastic multiple criteria decision making, Computers \& Industrial Engineering 58(4): 544-552. http://dx.doi.org/10.1016/j.cie.2009.12.001

Zhang, F.; Ignatius, J.; Lim, C. P.; Zhao, Y. 2014. A new method for deriving priority weights by extracting consistent numerical-valued matrices from interval-valued fuzzy judgement matrix, Information Sciences 279: 280-300. http://dx.doi.org/10.1016/j.ins.2014.03.120

Zhang, H.; Sekhari, A.; Ouzrout, Y.; Bouras, A. 2014. Optimal inconsistency repairing of pairwise comparison matrices using integrated linear programming and eigenvector methods, Mathematical Problems in Engineering 2014: 1-16. http://dx.doi.org/10.1155/2014/140140

Zhang, Z.; Wang, C.; Tian, X. 2015 Multi-criteria group decision making with incomplete hesitant fuzzy preference relations, Applied Soft Computing 36: 1-23. http://dx.doi.org/10.1016/j.asoc.2015.06.047

Zhu, B.; Xu, Z. 2014. Stochastic preference analysis in numerical preference relations, European Journal of Operational Research 237(2): 628-633. http://dx.doi.org/10.1016/j.ejor.2014.01.068 


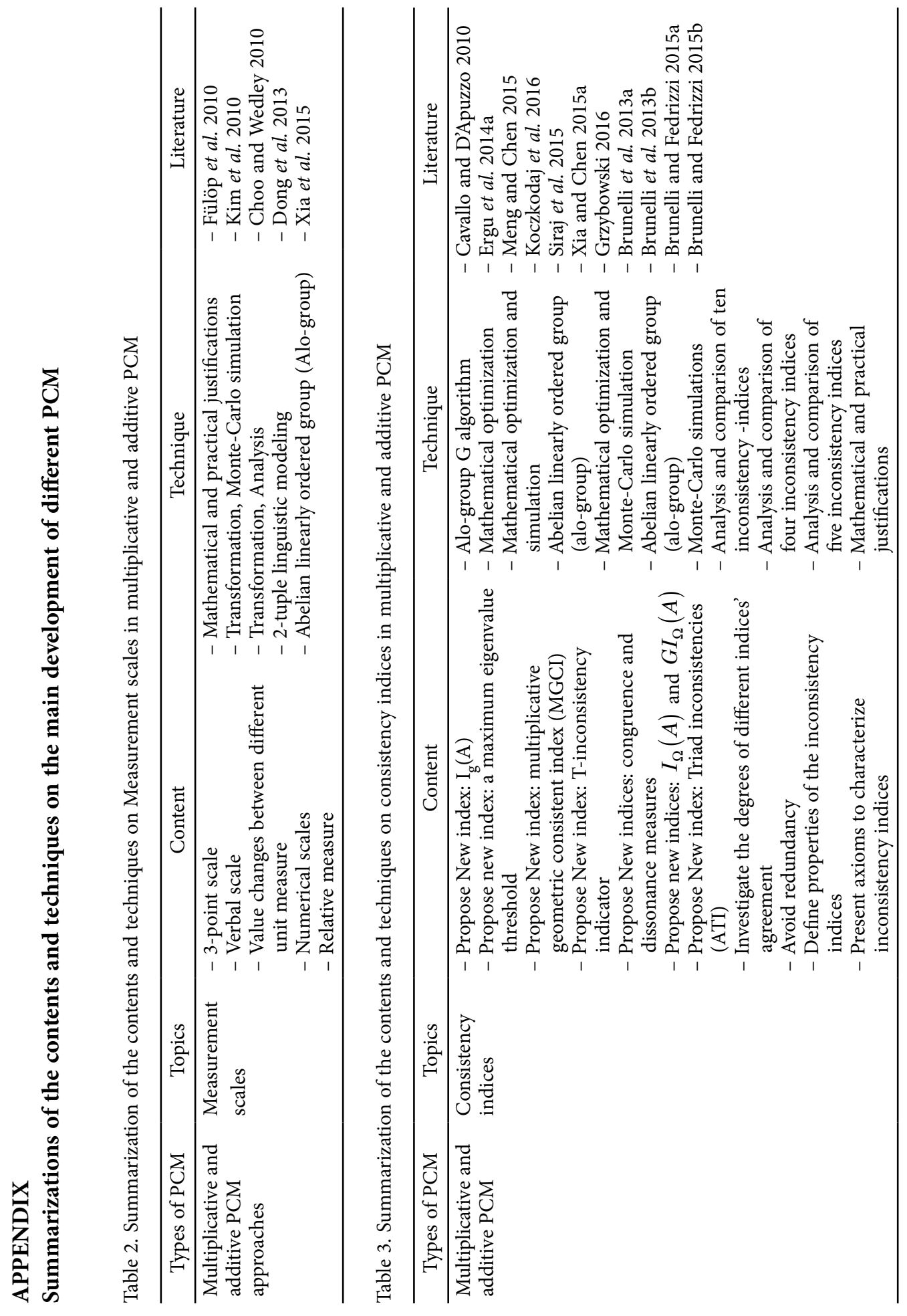




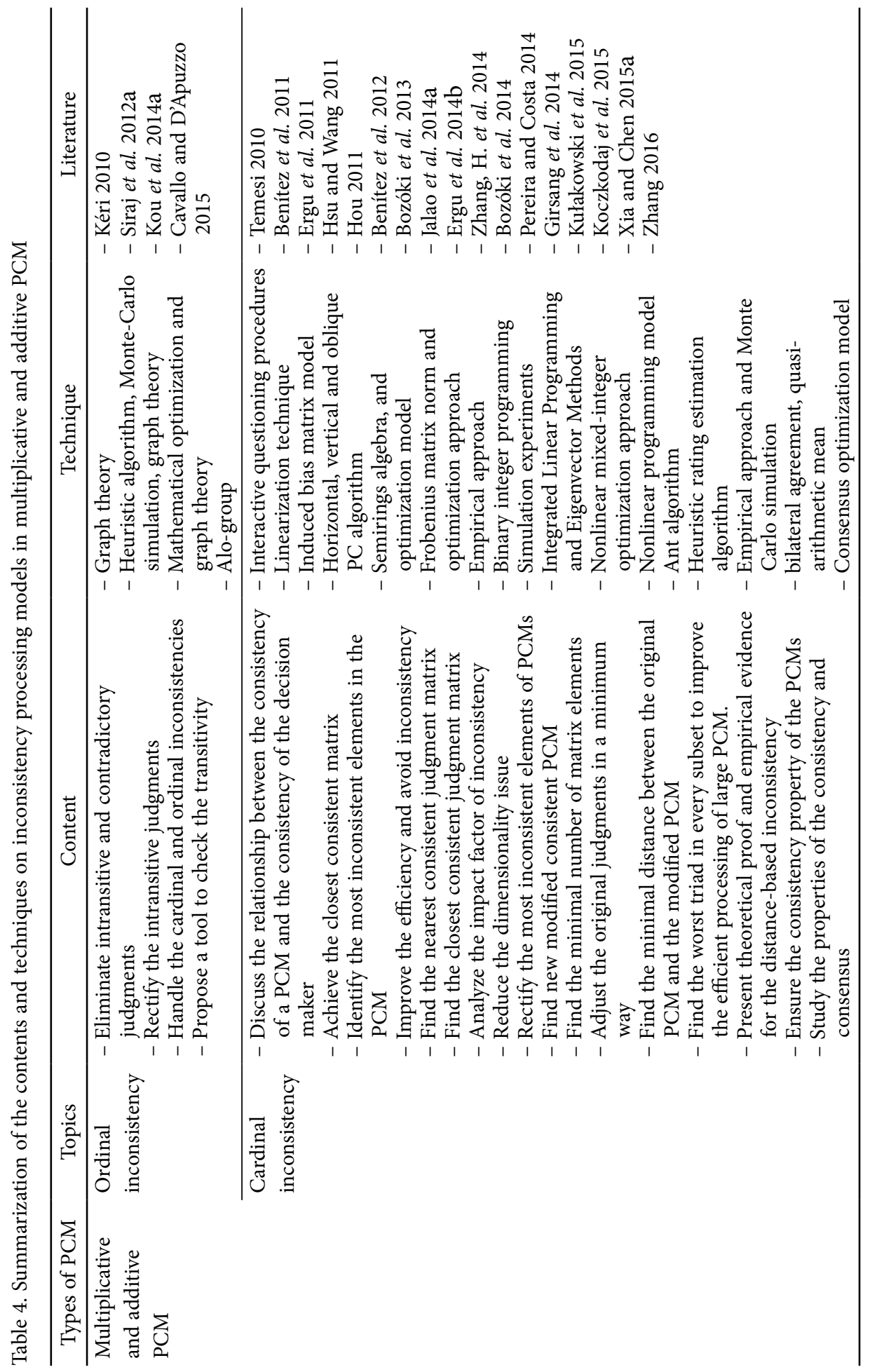




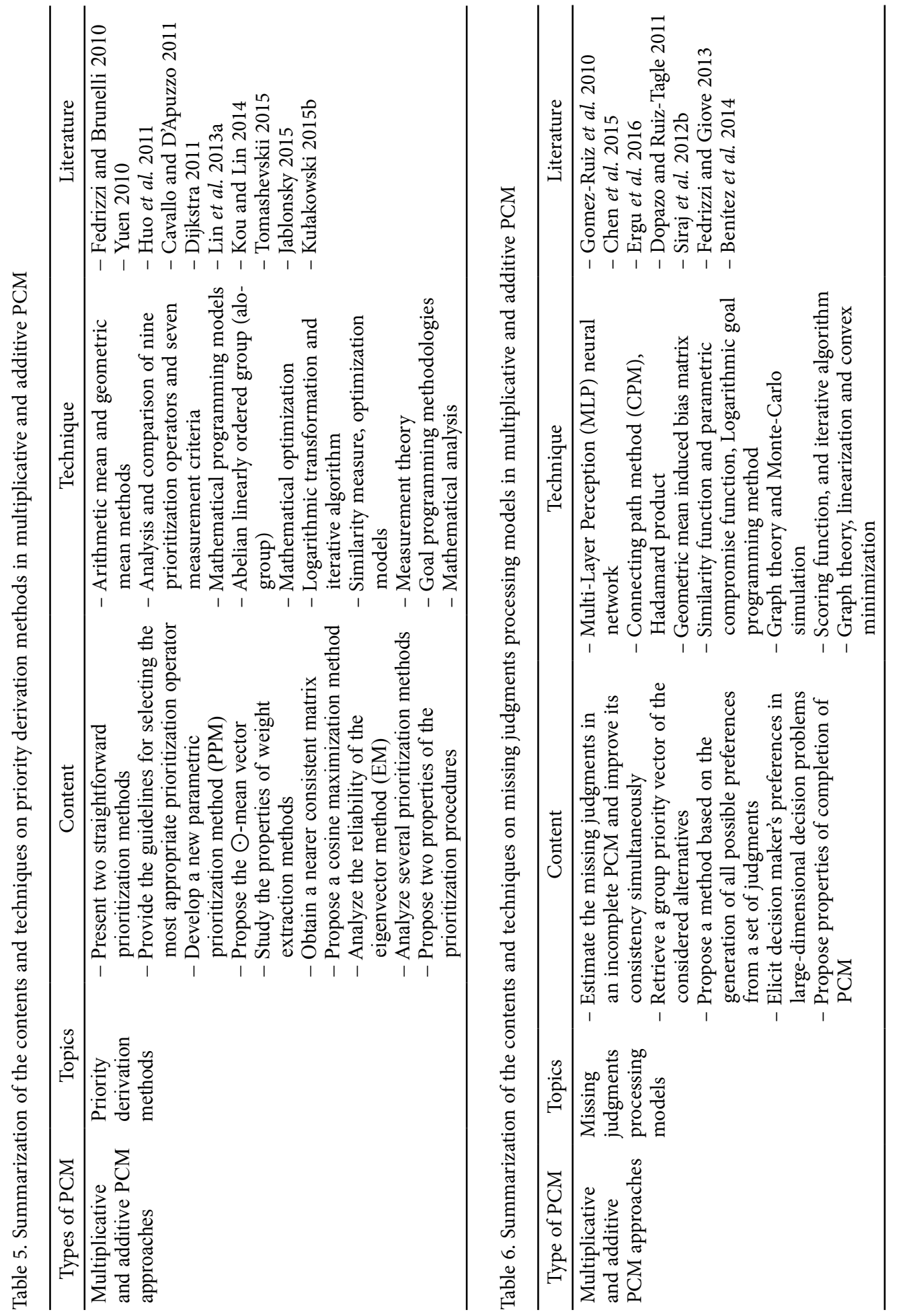




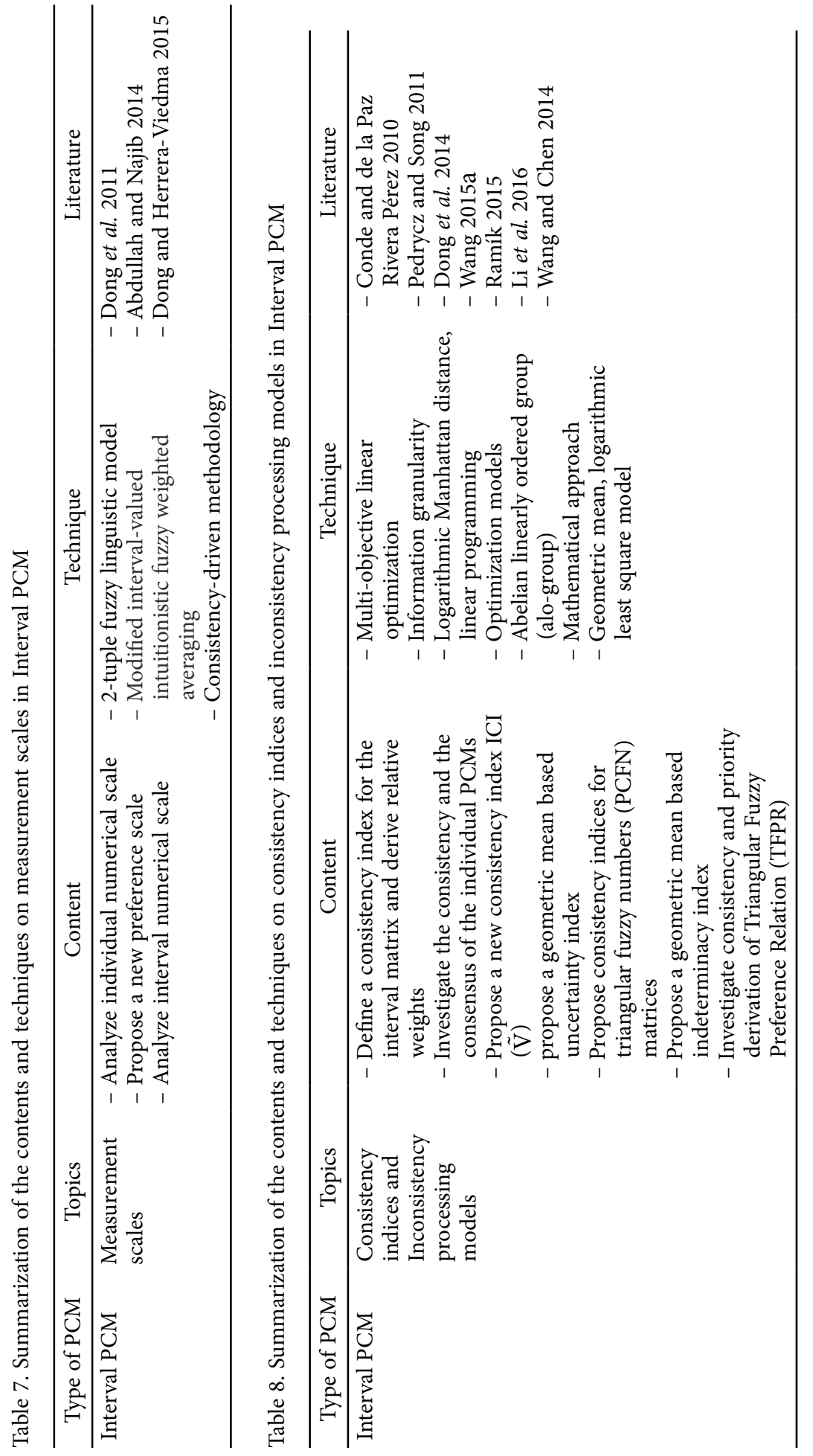



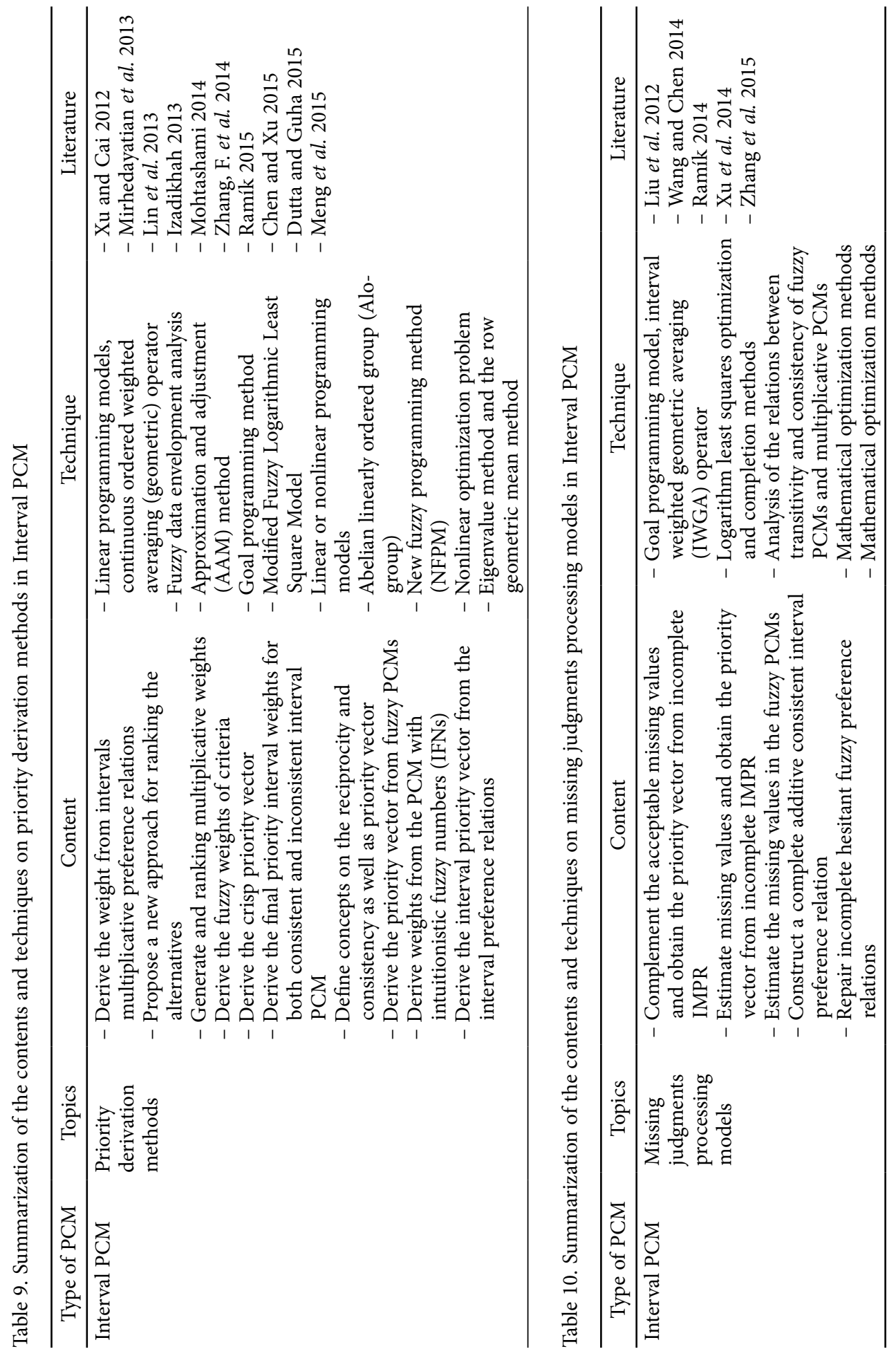

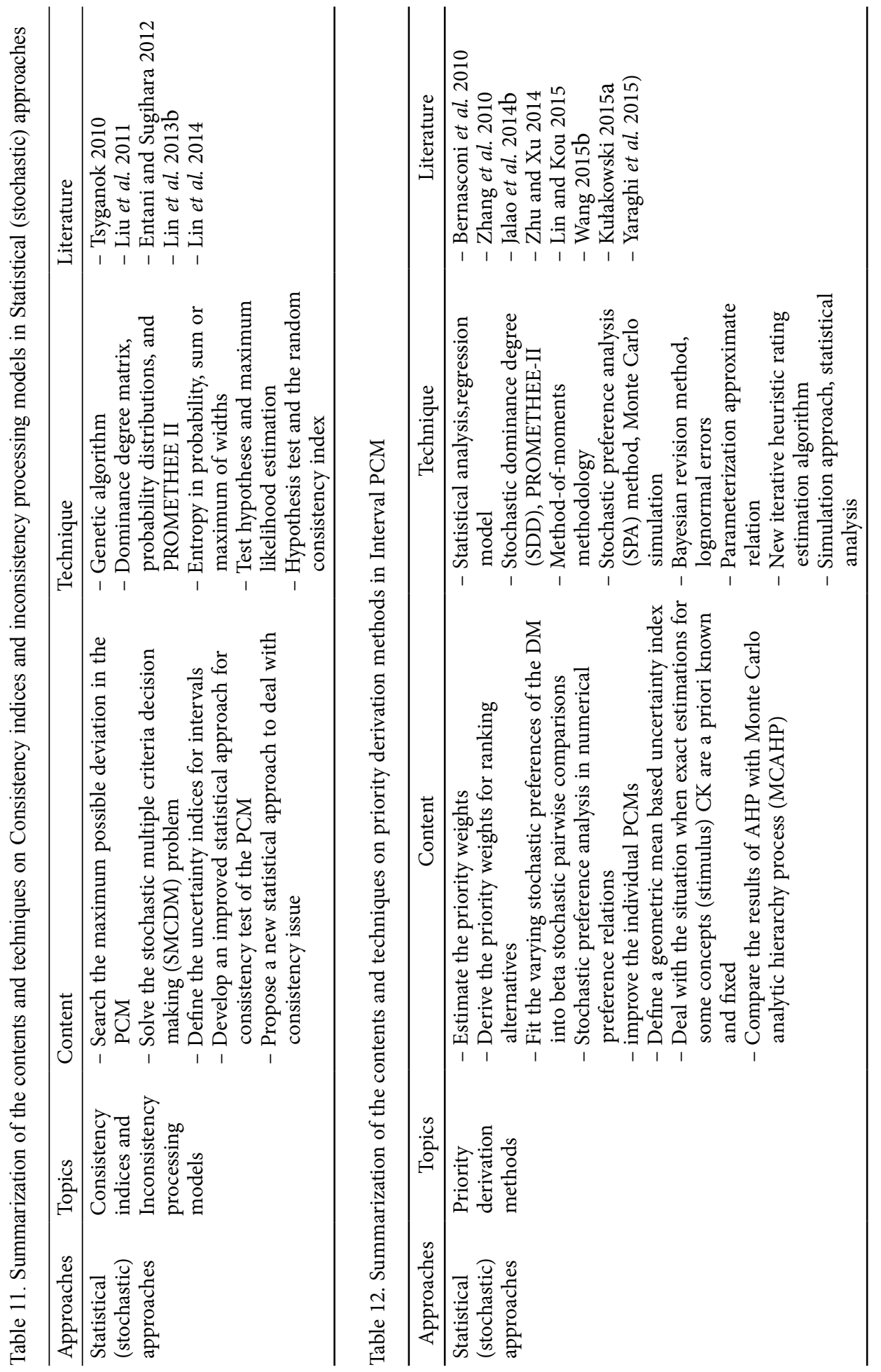
Gang KOU. Doctor, Professor. Executive dean of School of Business Administration, Southwestern University of Finance and Economics, China. Bachelor, Tsinghua University (1997). MS, University of Nebraska at Omaha (2003). PhD, University of Nebraska at Omaha (2006). Research scientist in Thomson Co., R\&D (2007-2008). The managing editor of International Journal of Information Technology \& Decision Making and editor-in-chief of Springer book series on Quantitative Management. Author of more than 100 scientific articles. Research interests: big data and data mining, credit risk analysis, multiple criteria decision making.

Daji ERGU. Doctor, Professor. College of Electrical \&Information Engineering, Southwest University for Nationalities, China. Bachelor degree in Applied electronic technology, Southwest University for Nationalities (1999). Master of Communications Management (2004). Doctor (2014). Research visits to Katz Graduate School of Business, University of Pittsburgh (USA, Aug. 2012 to Aug. 2013). Author of about 30 scientific articles. Research interests: risk analysis, emergency management and multiple criteria decision making.

Changshen LIN. Doctor, Associate Professor. School of mathematics and statistics, Yangtze Normal University, China. Bachelor degree in Mathematics and education, Hubei University for Nationalities (1998). Master of Science (2005). Doctor (2015). Author of about 7 scientific articles. Research interests: data analysis and multiple criteria decision making.

Yang CHEN. Doctor, Professor, Department of Management, School of Business Administration, Southwestern University of Finance and Economics, China. Bachelor degree in economics, Nanjing University (2008), Doctor in Management Information Systems, Hong Kong Baptist University (2011). Author of about 30 scientific articles. Research interests: corporate sustainability, IT business value, and human resource management. 